\title{
Integrated Study of Production Decline Analysis and Streamline Simulation on Haripur Oil Field
}

\author{
Mohammad Amirul Islam, A.S.M. Woobaidullah", and Badrul Imam \\ Department of Geology, Dhaka University, Dhaka 1000, Bangladesh
}

(Received: 9 August 2018; Accepted: 7 January 2019)

\begin{abstract}
In oil and gas industries there are available production data analysis tools and reservoir simulation techniques. Scientists and engineers use these tools and techniques to generate authentic and valuable information on the reservoir for planning and development. In this study production rate decline and streamline reservoir simulation are analyzed integrated way to determine the well life, flow rate, producible reserve, drainage volume and reserve. Well no SY-7 of Haripur oil field produced 0.531 million barrel of oil from 1987 to 1994. Exponential decline rate is matched with production profile and reveals well life of 10 years, producible reserve 0.7 million barrels. In addition, the drainage volume around the well is 158 million cubic feet estimated from the well life by using the streamline simulation, as well as the oil reserve 2 million barrels in the drainage volume is estimated. This reserve information carries value, authenticity and reliability for field development planning.
\end{abstract}

Keywords: Rate Decline, Streamline Simulation, Exponential Model, Well Drainage Volume, Oil Reserve.

\section{Introduction}

In oil and gas industries there are available production data analysis tools and reservoir simulation techniques. Scientists and engineers use these tools and techniques to generate authentic and valuable information on the reservoir for planning and development. Production rate decline and streamline reservoir simulation are analyzed in an integrated manner for reserve estimation F. Brons ${ }^{3}$. Two most popular decline curve techniques used in this study represent the decline in the oil or gas production rate with time, another technique is the plot of production rates versus cumulative oil or cumulative gas production, normally termed as rate-cumulative plots. With time production rate will be declined if there is no injection job. Production well drop to produce if oil rate of production well is below the economic limit (surface oil rate $<10$ bbl/day). The two basic points considered in appraisal work are the determination of most probable future life of wells and estimation of its future production.

The easy and logical way by extrapolation is to plot this variable production rate either against time or against cumulative production extending to the economic limit. The point of intersection of the extrapolated curve with the economic limit then indicates the possible future life or the future oil recovery. The future behavior of a production well will be strictly based on the past performance trend or mathematical relationship. Extrapolation method, thus, becomes a strictly empirical one and may make the results sometimes inferior than the more exact volumetric methods J. J. Arps ${ }^{4}$.

One of the major task of a petroleum engineer is to estimate oil reserves since it deals with usually depend on a comparison of the estimated cost in terms of barrels of oil C. W. N. $\mathrm{Jr}^{2}$. . In order to extrapolate decline curves with any degree of reliability to the reservoir productivity decline curve should not be affected from external causes, such as a change in production conditions, well damage, production controls, and equipment failure. A stable reservoir condition without any alteration like action taken to improve the recovery of oil, such as infill .drilling, fluid injection, fracturing, and acidizing, in the producing mechanism should prevail so that decline curve analysis can be used to estimate the performance .of the well or reservoir in the absence of the change B. K. Vansandt et al. ${ }^{1}$. This study is carried out to achieve the following objectives that include prediction of field reserve, type of driving mechanism, and comparing the results obtained to the company results.

\section{Oil Production Rate Decline}

Well no SY-7 of Haripur field produced oil from 01 December 1987 to 01 July 1994 and the oil production rates had been recorded in each month. As a natural manner the oil production rate has declined and finally the well has ceased the oil production after producing 0.531 million barrel of oil.

There are different decline models such as exponential decline, harmonic decline and hyperbolic decline available used by scientist and engineers. Oil production data has been plotted in different ways to identify a representative decline model.

Oil production rate (q) in stock tank barrel per day (STB/D) is plotted with time $(\mathrm{t})$ in month in semi log graph shown in figure 1 . The plot shows a straight line which yields the decline data follow an exponential decline model.

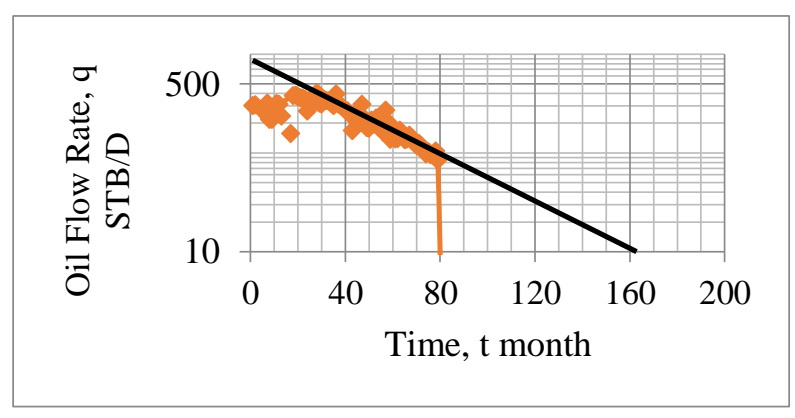

Fig. 1. Plot of $\log (q)$ versus $t$ 
The plot of - dq/dt.q versus $q$ shown in figure 2 has been plotted which produces a straight line where an exponential decline model should be adopted.

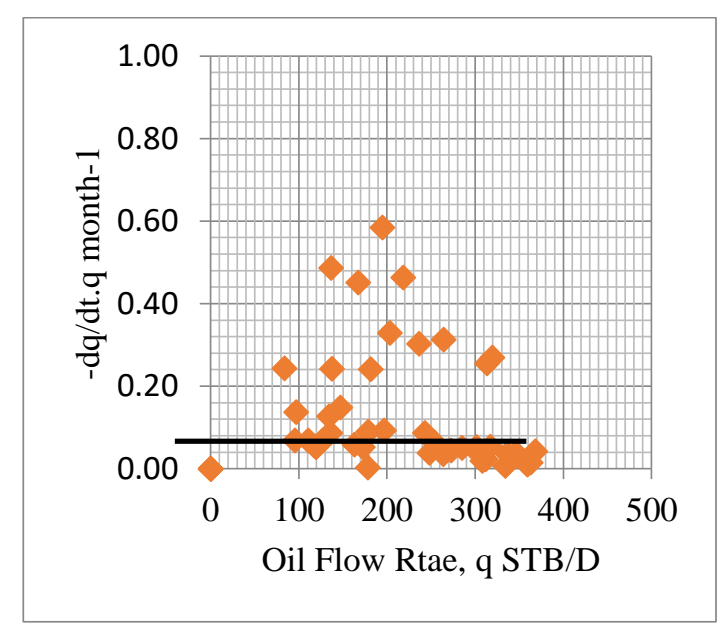

Fig. 2. Plot of - dp/dt.q versus Oil flow rate, $q$

The oil production rate by well no SY-7 was declined according to exponential model. An exponential model curve has been fitted in the $\mathrm{q}$ vs $\mathrm{t}$ plot shown in figure 3 . The exponential model line has been extrapolated in both ends to project the maximum oil production rate and the well life. The projected maximum oil production rate is 500 STB/D and the well life is 120 month i.e 3650 days.

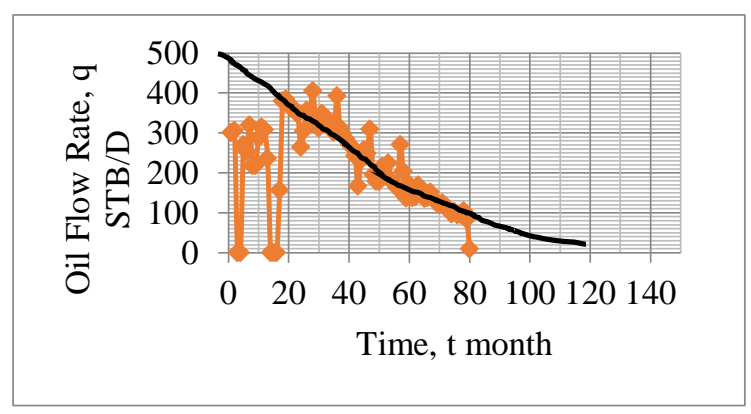

Fig. 3. Plot of Oil Flow Rate, $q$ versus Time, $t$

Cumulative production $(\mathrm{Np})$ has been plotted against $\mathrm{q}$ shown in figure 4. A straight line has been drawn and extrapolated in both sides to estimate the reserve and maximum oil production rate. The producible reserve is 0.7 million barrel.

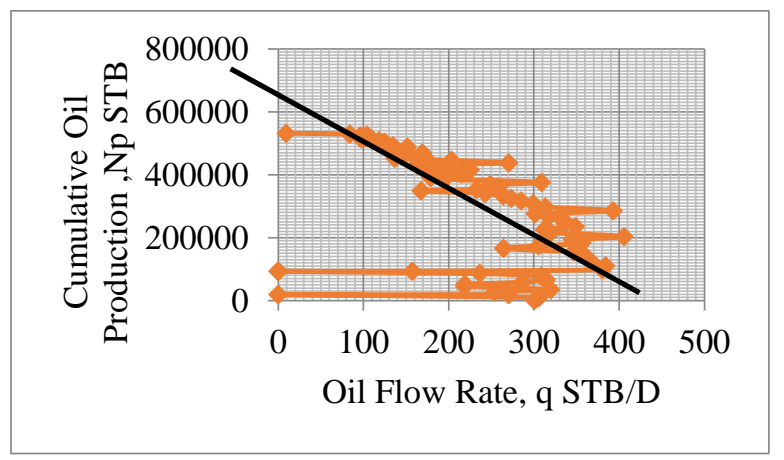

Fig. 4. Plot of Oil Flow Rate, q versus Cumulative Oil Production, Np

\section{Streamline Simulation}

A 3D reservoir model of the oil sand has been constructed using the seismic and well log data shown in figure 5 and the position of the oil producing well is placed in the model.

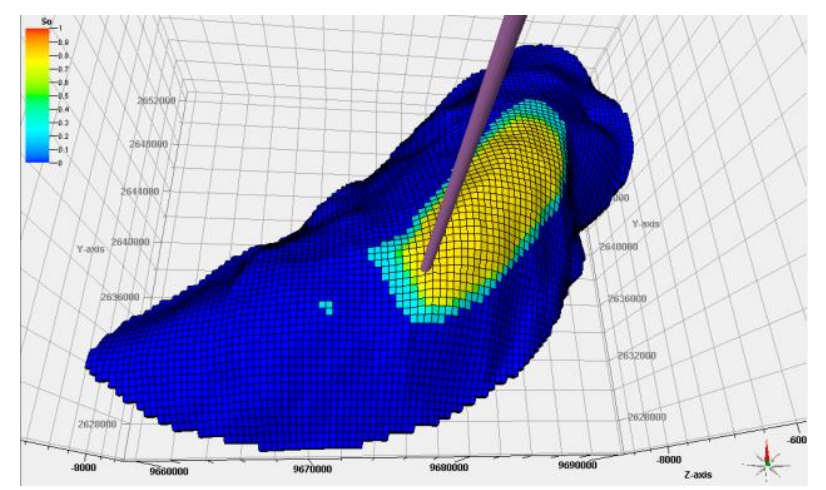

Fig. 5. Position of Oil Producing Well in the Reservoir Model

Stream line of simulation time is developed by running the simulation model shown in figure 6 . The simulation time scale ranging from 4000 days to 10000 days. The well life from decline analysis is estimated approximately 3650 days. Here polygon has been drawn around the 4000 days boundaries which represent the drainage volume of the well.

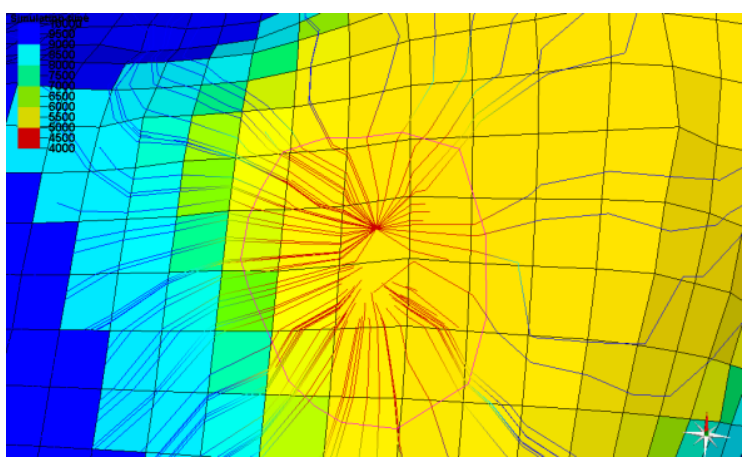

Fig. 6. Simulation Time Lines in the in the Drainage Zone of the Reservoir Model

Stream lines of the oil production rate in the drainage volume of the well are shown in figure 7 . The oil production rate is ranging from $0.001 \mathrm{STB} / \mathrm{D}$ to $0.1 \mathrm{STB} / \mathrm{D}$ in the drainage volume.

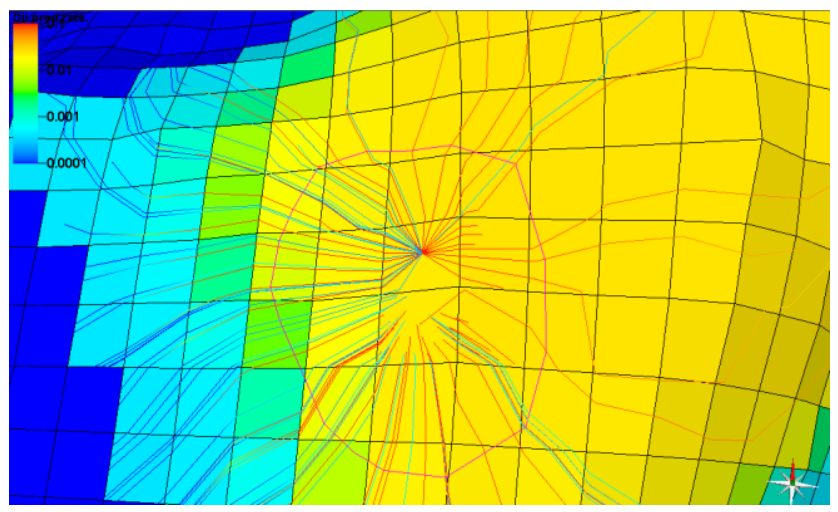

Fig. 7. Oil Production Lines in the Drainage Zone of the Reservoir Model 
The oil volume has been estimated using geological and engineering data such as grid dimensions, shale content, porosity, oil saturation, oil formation volume factor. The reserve estimation yields approximately 2 million barrel of oil is deposited in the drainage volume of the well shown in table 1.

Table 1. Oil Reserve Estimation

\begin{tabular}{|c|c|c|c|c|c|}
\hline $\begin{array}{l}\text { Bulk } \\
\text { volume } \\
{\left[* 10^{\wedge} 6\right.} \\
\mathrm{ft} 3]\end{array}$ & $\begin{array}{l}\text { Net } \\
\text { volume } \\
{\left[* 10^{\wedge} 6\right.} \\
\mathrm{ft} 3]\end{array}$ & $\begin{array}{l}\text { Pore } \\
\text { volume } \\
{\left[* 10^{\wedge} 6\right.} \\
\text { RB] }\end{array}$ & $\begin{array}{l}\mathrm{HCP} \\
\mathrm{V} \text { oil } \\
{\left[* 10^{\wedge}\right.} \\
6 \mathrm{RB}]\end{array}$ & 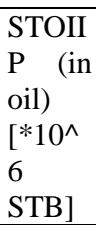 & $\begin{array}{l}\text { STOIIP } \\
{\left[* 10^{\wedge} 6\right.} \\
\text { STB }]\end{array}$ \\
\hline 158 & 158 & 4 & 3 & 2 & 2 \\
\hline
\end{tabular}

\section{Results}

Analysis of $\log (\mathrm{q})$ vs $\mathrm{t}$ and -dq/dt.q vs $\mathrm{q}$ profile reveals that the oil production decline is exponential decline model. The well life is 120 months estimated from the $q$ vs t plot. In addition the maximum flow rate is $500 \mathrm{STB} / \mathrm{D}$ obtained by extrapolating the exponential decline curve. Producible oil reserve is 0.7 million barrel estimated by extrapolating the $q$ vs $\mathrm{Np}$ curve. A 3D reservoir simulation has been constructed to perform the streamline simulation to delineate the well drainage volume. According to the simulation time 4000 days the established well drainage rock volume is 158 million cubic feet where 2 million barrel of oil is deposited as reserve.

\section{Conclusion}

Decline curve analysis is well established ancient and proven tools to analyze the production data for forecasting the oil flow rate, well life and reserve. Whereas the streamline simulation is newly developed power full tool to autopsy the reservoir. Streamline of simulation time, oil flow rate can be visualized by streamline simulation. Well life can be estimated by decline curve analysis and using this information the well drainage volume can be delineated and reserve can be estimated. The reserve information obtained from the integrated analysis of the rate decline and simulation is authentic and reliable for the decision making process of oil and gas field development.

\section{Acknowledgements}

Many of the referenced authors and others have shown great foresight and persistence to bring forward this technology; I wish to acknowledge their contributions.

\section{References}

1. Vansandt, B. K. et al., 1988, Gaudiness for application definitions for oil and gas reserves, Advances in Machanical Engineering (AIME), 192, 211-232.

2. C. W. N. Jr., 1924, Estimation of Underground Oil Reserves by Oil-Well Production Curves, Advances in Machanical Engineering (AIME), 145, 119-142.

3. Brons, F., 1963, On the Use and Misuse of Production Decline Curves, Advances in Machanical Engineering (AIME), 171, 215-241.

4. Arps, J. J., 1945, Analysis of Decline Curves, Trans. Advances in Machanical Engineering (AIME), 160, 228-247. 
